\title{
Genealógica Foucaultiana
} e práticas artísticas dissidentes: um reolhar sobre parte da produção da Artivista Brenda Bazante

Foucaultian Genealogy and dissident artistic practices: a new look at part of Artivist Brenda Bazante production

Genealogia Foucaultiana y praticas artísticas dissidentes: uma nueva mirada a parte de la producción de Artivista Brenda Bazante

\section{Brenda Gomes Bazante ${ }^{1}$}

Mestranda em Artes Visuais pela UFPE. Possui Graduação em Licenciatura em Artes Visuais pela Universidade Norte do Paraná (2018) e Especialização em Metodologia do Ensino de Artes pela Faculdade de Educação São Luis (2019). Atualmente é Diretora do Ateliê de Artes Visuais Flor de Antúrio e possui experiência na área de Artes com ênfase em escultura e Arte Cinética. E-mail: brendabazante@live.com.

Currículo Lattes: http://lattes.cnpq.br/2302455310889408 


\title{
Resumo
}

Neste artigo procuro entender como despertei para a necessidade de aliar práticas artísticas e militância transfeminista, reforçando a vanguarda artivista que atua a partir de temas ligados à desobediência de gênero. Para isso conduzi um novo olhar (reolhar) sobre duas ações que protagonizei no campo educativo e visual, tendo como caminho metodológico a Genealogia Foucaultiana e sua relação com a História. Nesse trajeto adaptei a proposta de Foucault para reobservar os registros tanto da Performance Mimetismo realizada em 2014, quanto de duas oficinas de origamis ministradas durante a Exposição Galhos em 2017. Na reapreciação aqui descrita, aponto principalmente pistas e vestígios de ações/gestos artísticos que indicaram a presença de posturas críticas ligadas às questões política, social, artivista e de dissidência de gênero. O panorama teórico foi formado pelos conceitos de Genealogia e História de Michel Foucault (1979), Arte e Política de Jacques Rancière (2012), Performatividade de Gênero de Judith Butler (2020), Contrassexualidade de Paul B. Preciado (2017), Reinvenção do Corpo de Berenice Bento (2006), Transfeminismo de Jaqueline de Jesus (2014) e outros. Por fim, considero que a compreensão da experiência transexual ocorrerá de forma mais fácil caso ela seja estudada e representada por meio de diversos campos do conhecimento, entre eles a Arte-Educação. Também entendo que essa experiência será potencializada no contato direto com o público, seja por meio de atividades artísticas que contenham a temática trans ou pela simples presença de uma pessoa trans propondo tais ações. Além disso, percebo que as características artivistas e dissidentes, presentes nas produções que atualmente desenvolvo, foram criadas gradualmente a cada ação. Elas foram gestadas nas práticas sutilmente desobedientes realizadas desde 2014 e hoje extrapolam reflexões para além de meu fazer artístico.

\section{Palavras-chave}

Transexualidade; Genealogia Foucaultiana; Educação; Práticas Artísticas.

\begin{abstract}
In this article, i try to understand how $\mathrm{i}$ woke up to the need to combine artistic practices and transfeminist activism, reinforcing the artivist vanguard that works from themes related to gender disobedience. For that, i conducted a new look (to look back) on two actions that $\mathrm{i}$ carried out in the educational and visual field, using Foucault's Genealogy and its relationship with History as a methodological path. Along this path, i adapted Foucault's proposal to reobserve the records of both the Performance Mimetism held in 2014, as well as two origami workshops given during the Galhos Exhibition in 2017. In the review described here, i mainly point out clues and traces of artistic actions/gestures that indicated the presence of critical attitudes related to political, social, artivist and gender dissident issues. The theoretical panorama was formed by the concepts of Genealogy and History by Michel Foucault (1979), Art and Politics by Jacques Rancière (2012), Gender Performativity by Judith Butler (2020), Contrassexuality by Paul B. Preciado (2017), Reinvention of the Body by Berenice Bento (2006), Transfeminism by Jaqueline Jesus (2014) and others. Finally, i believe that understanding of the transsexual experience will occur more easily if it is studied and represented through several fields of knowledge, including art education. I also understand that this experience will be enhanced in direct contact with the public, either through artistic activities that contain the trans
\end{abstract}




\section{Keywords}

Authorial photography; memory; objects of affection; house-body; education-al action.

\section{Resumen}

En este artículo trato de entender cómo me desperté ante la necesidad de combinar prácticas artísticas y activismo transfeminista, reforzando la vanguardia artivista que trabaja desde temas relacionados con la desobediencia de género. Para ello realicé una nueva mirada (mirar atrás) sobre dos acciones que realicé em el campo educativo y visual, utilizando la Genealogía de Foucault e sua relación com la Historia como camino metodológico. En este camino, adapté la propuesta de Foucault para volver a observar los registros tanto del Mimetismo Performance realizado en 2014, como de dos talleres de origami impartidos durante la Exposición Galhos em 2017. En la reseña aquí descrita, señalo principalmente pistas y rastros de acciones/gestos artísticos que indicaron la presencia de actitudes críticas relacionadas con temas políticos, sociales, artivistas y disensión de género. El panorama teórico lo conformaron los conceptos de Genealogía y Historia de Michel Foucault (1979), Arte y Politica de Jacques Rancière (2012), Performatividad de Género de Judith Butler (2020), Contrassexualidad de Paul B. Preciado (2017), Reinvención del Cuerpo de Berenice Bento (2006), Transfeminism de Jaqueline Jesus (2014) y otros. Finalmente, creo que la comprensión de la experiencia transexual occurirá más facilmente se si estudia y representa a través de varios campos de conocimiento, incluida la educación artística. También entendo que esta experiencia se potenciará en contacto directo con el público, ya sea a través de actividades que contengan la temática trans o por la simple presencia de una persona trans que proponga tales acciones. Además, me doy cuenta de que las características de artivistas y dissidentes, presentes em las producciones que actualmente desarrollo, se fueron creando paulatinamente com cada acción. Fueron creadas em las prácticas sutilmente desobedientes realizadas de 2014 y hoy extrapolan reflexiones más allá de mi práctica artística.

\section{Palavras-chave}

Transexualidad; Genealogía Foucaultiana; Educación; Prácticas Artísticas.. 


\section{Aproximações entre Genealógica Foucaultiana, História e questões relativas à dissidência de gênero}

Em Microfísica do Poder, Foucault (1979) relaciona genealogia e história dizendo que a primeira "é cinza, ela é meticulosa e pacientemente documentária. Ela trabalha com pergaminhos embaraçados, riscados e várias vezes reescritos" (FOUCAULT, 1979, p. 15). Aproximando essa abordagem das experiências de pessoas transgêneras, passo a enxergar suas corporalidades transexuais como palimpsestos, corpos escritos, parcialmente apagados e reescritos ou "inconclusos, desfeitos e refeitos, arquivos vivos de histórias de exclusão", como afirma Berenice Bento (2006, p. 19), importante pesquisadora da temática trans no cenário brasileiro.

Enquanto mulher transexual também vivencio essa exclusão, entendo o quanto é difícil viver no país que mais mata a população LGBTIAP+ (Lésbicas, gays, bissexuais, transexuais, intersexuais, assexuais, pansexuais e mais) no mundo. Pessoas inseridas num sistema para o qual "o corpo é um texto socialmente construído, um arquivo orgânico da história da humanidade como história da produção-reprodução sexual" (PRECIADO, 2017, p. 26). Organismo social em que "certos códigos se naturalizam, outros ficam elípticos e outros são sistematicamente eliminados ou riscados" (ibidem), sobretudo as existências travestis/transexuais. Mulheres que têm a coragem de externar/viver as suas performatividades, como afirma Butler (2020), expondo seus desejos e modos/estilos de vida, consequentemente tornando-se "os alvos preferidos das pedagogias corretivas e das ações de recuperação ou de punição. Para eles e para elas a sociedade reservará penalidades, sanções, reformas e exclusões" (LOURO, 2004, p. 16).

Diante desse cenário, qualquer artista LGBTIAP+ que se encontra nessa posição marginalizada e pretende agir politicamente através de sua arte, naturalmente toma a decisão de enfrentar tal situação, já que, "como distorção do ser mais, o ser menos leva os oprimidos, cedo ou tarde, a lutar contra quem os fez menos" (FREIRE, 2011, p. 41). Enquadro-me nesse panorama. Logo, nesse enfrentamento assumo uma postura transfeminista que, entre outras coisas, "reconhece a história de luta das travestis e das mulheres trans e as experiências pessoais da população transgênero de forma geral" (JESUS, 2014, s.p.). Sendo assim, junto-me às demais ativistas aliando práticas artísticas à militância trans. A metodologia que empreguei para adentrar esse caminho foi a reobservação genealógica da trajetória a/r/tográfica - método de pesquisa nas artes que envolve, simultaneamente, ações/práticas artísticas, de pesquisa e de docência - que desenvolvi no campo das visualidades nos últimos seis anos, focando principalmente no intervalo entre 2014 e 2017. Nesta empreitada, emprego a proposta genealógica de Foucault (1979) em sua relação com a História e inicio uma reanálise em torno de minha curta, mas importante, jornada nas Artes Visuais, Educação, pesquisa e militância.

Ao relacionar Genealogia e poder, Foucault (1979) decide chamá-la momentaneamente de "o acoplamento do conhecimento com as memórias locais, que permite a constituição de um saber histórico das lutas e a utilização deste saber 
nas táticas atuais" (FOUCAULT, 1979, p. 171). Nesse processo, que não é empírico ou positivista, devem ser trazidos para a superfície "saberes locais, descontínuos, desqualificados, não legitimados, contra a instância teórica unitária que pretenderia depurá-los, hierarquizá-los, ordená-los em nome de um conhecimento verdadeiro" (ibidem). Entretanto, a proposta genealógica não pretende se opor à ciência. Ela quer estabelecer "uma insurreição dos saberes antes de tudo contra os efeitos de poder centralizadores que estão ligados à instituição e ao funcionamento de um discurso científico organizado no interior de uma sociedade como a nossa" (FOUCAULT, 1979, p. 171).

A partir deste ponto Foucault (1979) começa a questionar como as ciências são constituídas e problematiza que tipos de saberes e sujeitos foram desconsiderados para que estas ciências fossem estabelecidas. Em seguida o filósofo apresenta outra possível definição para a Genealogia dizendo que ela "seria um empreendimento para libertar da sujeição os saberes históricos, isto é torna-los capazes de oposição e de luta contra a coerção de um discurso teórico, unitário, formal e científico" (FOUCAULT, 1979 , p. 172). Ou seja, "a reativação dos saberes locais [...] contra a hierarquização científica do conhecimento e seus efeitos intrínsecos de poder, eis o projeto destas genealogias desordenadas e fragmentadas" (ibidem). Assim sendo, a Genealogia Foucaultiana se opõe "ao desdobramento meta-histórico das significações ideais e das indefinidas teleologias. Ela se opõe á pesquisa de origem" (FOUCAULT, 1979, p. 16). Neste ponto é importante dizer que, diferente da metafísica e da pesquisa de origem, essa teoria não está interessada em

\footnotetext{
Um ponto único entendido como a origem de tudo, em vez disso buscamos, na dispersão dos acontecimentos, os diferentes começos possíveis. Tratase de compreender que a constituição de um objeto é o resultado do entrecruzamento de uma variedade de práticas e discursos que tornaram possível sua existência em um dado momento histórico (KLAUS et al, 2015, p. 668).
}

Ao invés de procurar uma origem, o genealogista prefere "se demorar nas meticulosidades e nos acasos dos começos; [...] esperar vê-los surgir, máscaras enfim retiradas, com o rosto do outro; não ter pudor de ir procurá-las lá onde elas estão, escavando os basfond" (FOUCAULT, 1979, p. 19). Quando escrevem sobre Genealogia, tanto Foucault (1979) quanto Klaus (2015) sugerem uma reanálise dois fatos históricos fugindo da linearidade e da origem em direção à proveniência. Para Foucault a pesquisa da proveniência desestabiliza "o que se percebia imóvel, ela fragmenta o que se pensava unido, ela mostra a heterogeneidade do que se imaginava em conformidade consigo mesmo" (1979, p. 21) e sugere focar e "demarcar os acidentes, os íntimos desvios - os erros, as falhas na apreciação, os maus cálculos que deram nascimento ao que existe e tem valor para nós" (ibidem). Em outras palavras, dar valor àqueles fatos que foram considerados sem importância. Sem esquecer que a História é escrita pelos vencedores e que os acontecimentos protagonizados pelos dominados, ou aqueles que não se enquadram nas normas estabelecidas, são deixados à parte e esquecidos, como afirma Foucault (1979). 
Ainda segundo o autor a pesquisa de proveniência revela esse estado de dominação e as forças nele envolvidas (FOUCAULT, 1979). O esforço dos subjugados que, por sua vez, traz à tona a emergência que pode ser definida como "a entrada em cena das forças; é sua interrupção, o salto pela qual elas passam dos bastidores para o teatro, cada uma com seu vigor e sua juventude" (FOUCAULT, 1979, p. 24). Libertação que pode ser comparada ao levante dos oprimidos contra o opressor, como defende Freire (2011). Mas como a Genealogia Foucaultiana adequa-se ao que discuto neste artigo? De que forma ela pode me ajudar a explicar essa postura artivista transfeminista que assumo nas práticas artísticas que venho elaborando? Para responder a essas questões debruço-me sobre os registros das seguintes ações: duas oficinas realizadas durante as edições da Exposição Galhos no ano de 2017, mostras compostas por esculturas móveis feitas com gravetos e origamis; e a performance Mimetismo realizada juntamente com o Artista Raurício Barbosa no Dia do Frevo de 2014, em Olinda/PE.

Como pode ser observado na proposta genealógica de Foucault, a História precisa ser encarada com outros olhos em busca de detalhes despercebidos ou considerados inferiores. Adaptando esse percurso para a realidade que vivencio, investiguei novamente os registros e as memórias da performance e das oficinas, acima mencionadas, em busca de condutas transfeminista/artivistas escondidas atrás do trabalho de Artes Visuais e de Educação Não Formal. Essas duas ações são a História que reanalisei genealogicamente. A História das práticas artísticas e educativas que desenvolvi entre 2014 e 2017. Realizações que até pouco tempo - antes de começar o Mestrado no Programa Associado de Pós-Graduação em Artes Visuais (PPGAV) UFPE/UFPB - enxergava apenas pelo viés da arte-educação, analisando seu valor nas Artes Visuais e na Educação sem me preocupar com questões de militância/ artivismo/transfeminismo. Porém, ao revirar, genealogicamente, tanto as fotos quanto as lembranças destas duas ações, consigo perceber sutilezas que, indiretamente, alimentaram essa vontade de transgredir as normas de gênero por meio da arte. Atitude que hoje se manifesta quando incluo nas práticas artísticas que desenvolvo questões relativas à dissidência de gênero. Mas, como sugere Foucault (1979) não faço essa investigação desejando encontrar uma linha de partida. Pelo contrário, me esgueiro pelos cantos e reobservo essas produções percebendo vestígios de uma arte crítica, de discussões sociais, políticas e de dissidência de gênero que já estivessem presentes.

Esse percurso genealógico alimenta a Pesquisa "Cadê as Travas Transcorpocinéticas?", em desenvolvimento no PPGAV UFPE/UFPB. Nessa investigação procuro entender como representar os corpos de mulheres trans/travestis por meio da Arte Cinética - linguagem que exploro desde 2016. Paralelamente a este período de quatro anos, realizei algumas performances, práticas artísticas e diversas ações no âmbito da educação formal e não formal, como oficinas e palestras. A Genealogia Foucaultiana, em sua relação com a História adaptada a reobservação de minha produção, ajudou a descobrir as pistas que me levaram a concluir que não basta apenas ir às salas de aula e falar sobre transgeneridade e, paralelamente, 
produzir esculturas móveis com materiais recicláveis. Ela deu suporte à compreensão da necessidade de aliar essas práticas, ou seja, me fez perceber que era preciso levar as discussões de gênero para as práticas artísticas e as duas para a educação.

Todavia, essa tarefa não busca um começo para a união de arte e militância no meu fazer artístico. Essa afirmação apoia-se num questionamento feito por Foucault (1979) acerca da recusa, ocasional, de Nietzsche pela pesquisa de origem. Em seguida ele responde dizendo que nesse processo perde-se os acidentes e "todas as peripécias que puderam ter acontecido, todas as astúcias, todos os disfarces" (FOUCAULT, 1979, p. 17), apenas para tentar "desvelar uma identidade primeira" (ibidem). Diferentemente, se unirmos genealogia e história percebemos que "atrás das coisas 'há algo extremamente diferente': não seu segredo essencial e sem data, mas o segredo que elas são sem essência, ou que sua essência foi construída peça por peça a partir das figuras que lhe eram estranhas" (FOUCAULT, 1979, p. 18).

Ora, vejo aqui um ponto de entrada para as questões de gênero, uma vez que a cisnormatividade ${ }^{1}$ compulsória é atribuída a todos os sujeitos logo após seu nascimento. Em outras palavras, a sexualidade é elaborada nos indivíduos obedecendo "limites que se estabelecem sempre nos termos de um discurso hegemônico, baseado em estruturas binárias que se apresentam como a linguagem da racionalidade universal" (BUTLER, 2020, p. 30). Um discurso no qual o binário homem/pênis e mulher/vagina dita a "normalidade" determinando quem é menino e menina, respectivamente. Mas existem corpos que escapam desse determinismo biológico, pois "o gênero é culturalmente construído: consequentemente, não é nem o resultado causal do sexo nem tampouco tão aparentemente fixo quanto o sexo" (BUTLER, 2020, p. 26). Entretanto, precisamos ficar atentos, pois

Ao compreender parcialmente o gênero como construção social, o feminismo dito tradicional ou essencialista reforça estereótipos sobre os corpos e os seus usos prejudiciais não apenas à população transgênero, mas a todo e qualquer ser humano que não se enquadre no modelo que iguala sexo a gênero (JESUS, 2014, s.p.).

Nessa fala, Jaqueline de Jesus (2014), importante militante transfeminista brasileira, quer chamar atenção para as pessoas que tensionam as normas da binaridade de gênero para além das identidades cis ou trans e da orientação sexual. Ela apresenta elementos que ampliam a discussão sobre o conceito de gênero que Butler (2020), ao analisar os atos corporais subversivos, passa a entender "como um estilo corporal, um 'ato', por assim dizer, que tanto é intencional como performativo" (BUTLER, 2020, p. 240). A filósofa americana segue sua linha de raciocínio expondo a situação compulsória à qual essa performance está atrelada e a punição para aqueles que a desobedecem e não a desempenham de forma correta. Porém Preciado (2017) crítica, especificamente, este trecho de sua teoria ao defender que "o gênero não é simplesmente performático. [...] É, antes de tudo, prostético, ou seja, não se dá

1 A cisnormatividade pode ser entendida como uma concepção em que a identidade de gênero deve ser compatível com o sexo biológico, ou seja, quem nasce com a genitália masculina deve se entender como homem. 
senão na materialidade dos corpos. É puramente construído e ao mesmo tempo inteiramente orgânico" (PRECIADO, 2017, p. 29).

Sobre a construção do corpo na História, Foucault (1979) diz que nos enganamos ao pensar que apenas a biologia age sobre as corporalidades. Segundo o autor "o corpo traz consigo, em sua vida e em sua morte, em sua força e em sua fraqueza, a sanção de todo erro e de toda verdade como ele traz consigo também e inversamente sua origem - proveniência" (FOUCAULT, 1979, p. 22). Mais adiante, o autor amplia essa problematização destacando que o corpo, que não escapa da História, "é formado por uma série de regimes que o constroem; ele é destroçado por ritmos de trabalho, repouso e festa; ele é intoxicado por venenos [...] e leis morais simultaneamente; ele cria resistência" (FOUCAULT, 1979, p. 27).

Como contraponto às relações acima expostas, Federici (2017), autora da Obra Calibã e a bruxa, oferece uma perspectiva interessante. Para a autora "o caráter quase defensivo da teoria de Foucault sobre o corpo se vê acentuado pelo fato de que considera o corpo como algo constituído puramente por práticas discursivas" (FEDERICl, 2017, p. 34). Nesse exame, o filósofo francês estaria "mais interessado em descobrir como se desdobra o poder do que identificar sua fonte. Assim, o poder que produz o corpo aparece como uma entidade autossuficiente, metafísica, ubíqua, desconectada das relações sociais e econômicas" (ibidem). Essa reflexão pode ser comprovada na passagem em que Federici (2017) traz a caça às bruxas para a discussão. Segundo a escritora,

A teoria foucaultiana só pode ser defendida à custa de omissões extraordinárias. A mais óbvia é a omissão da caça às bruxas e do discurso sobre a demonologia na sua análise sobre o disciplinamento do corpo. Sem dúvida, se essas questões tivessem sido incluídas, teriam inspirado outras conclusões, já que ambas demonstram o caráter repressivo do poder aplicado contra as mulheres e o inverossímil da cumplicidade e da inversão de papéis que Foucault, em sua descrição da dinâmica dos micropoderes, imagina que existem entre as vítimas e seus perseguidores (FEREDICl, 2017, p. 35).

Reconheço a necessidade de incluir nas análises que envolvem corpo, história e poder, as questões sociais, étnicas e de dissidência de gênero. Inclusive apoiando-me em Butler, para quem

Tanto na superfície, quanto no seu interior, o corpo é um fenômeno social: ele está exposto aos outros, é vulnerável por definição. Sua mera sobrevivência depende de condições e instituições sociais, o que significa que, para 'ser' no sentido de sobreviver, o corpo tem que contar com o que está fora dele [...] Ele não é, contudo, uma mera superfície na qual são inscritos significados sociais, mas sim o que sofri, usufrui e responde à exterioridade do mundo, uma exterioridade que define sua disposição, sua passividade e atividade (2018, p. 57-58). 
Essas problematizações das teorias foucaultianas são importantes e contextualizam o seu estudo no cenário atual. Futuramente aprofundarei essas ausências de contextualização denunciadas por Federici (2017). Por hora, foco nos aspectos genealógicos relativos à procura por vestígios de saberes despercebidos ou ignorados nas práticas artísticas mencionadas neste artigo. Neste sentido, retorno para as questões ligadas à arte, mas sem abandonar a discussão sobre diversidade sexual, pois a avaliação de Preciado (2017), ligada ao caráter prostético dos gêneros e à materialidade dos corpos, orienta a pesquisa que desenvolvo para a construção de uma escultura cinética que dê conta de representar o corpo trans. Ao mesmo tempo, essa prática artística exigirá um exame genealógico de minhas transformações corporais, pois "enquanto estiver neste processo de criação, estarei pesquisando e experimentando diversos materiais e tentando conectar-me com minha subjetividade" (BAZANTE, 2020, p. 205). Atividade na qual pretendo extrair das memórias e vivências de meu corpo referências que alimentem o processo criativo. Uma vez que o foco da escultura móvel que pretendo construir será o movimento da corporalidades trans/ travestis ao longo do tempo. Movimento oriundo de transformações nas esferas cirúrgica, estética e endocrinológica, corroborando o pensamento de Preciado (2017) sobre o caráter prostético da construção do gênero. A essa ação dou o nome de Transcorpocinetismo, conceito em desenvolvimento no PPGAV UFPE/UFPB.

Além disso, analisei os aspectos educativos presentes na performance e nas oficinas, pois este breve estudo genealógico ao redor de práticas artísticas anteriormente elaboradas, é parte integrante da Pesquisa "Cadê as Travas Transcorpocinéticas?", investigação que utiliza a A/r/tografia como metodologia. Sendo assim, as práticas docentes, tanto formais quanto não formais construídas em conjunto com a pesquisa e com a arte - a exemplo das oficinas de origamis da Expo Galhos, têm um papel relevante neste percurso. Logo, ao debruçar-me sobre as ações educativas desenvolvidas em 2014 e 2017 em busca de aspectos artivistas e transfeministas, encontrei referências que podem estimular o pensamento a/r/tográfico construído no Mestrado em Artes Visuais e, obviamente, respondi os questionamentos levantados neste artigo.

Nos registros e memórias das duas oficinas oriundas da Expo Galhos existem pequenos detalhes que revelam como aliar essas práticas à pesquisa e à ação docente. É nesse sentido que a reobservação genealógica de minha breve história enquanto artista, professora e pesquisadora alimentará a abordagem a/r/tográfica desenvolvida no PPGAV. Segundo Dias (2013) a A/r/tografia é uma metodologia de pesquisa que une práticas artísticas, de pesquisa e de docência. Igualmente, é "uma forma de representação que privilegia tanto o texto (escrito) quanto a imagem (visual) quando eles se encontram em momentos de mestiçagem ou hibridação" (DIAS, 2013, p. 25). O olhar curioso, criativo e genealógico sobre as ações pedagógicas aqui descritas revelou essas imagens a/r/tográficas. Os registros das oficinas de origamis e as lembranças que surgem a partir de sua contemplação estão carregados de ensinamentos úteis a este estudo. Então os reobservo entendendo que "a docência se faz na junção de fragmentos do cotidiano, na costura de pedaços de vivências dentro 
e fora da sala de aula e na projeção de experiências que nos levem a compartilhar alunos e professores - reflexões e significados que vivemos" (TOURINHO, 2013, p. 23 $6)$.

Essa discussão transborda para a escola que representa uma alternativa para as travestis se afastarem das margens nas quais foram colocadas e galgarem uma posição mais central no corpo social, como defende Andrade (2012). Neste sentido, revirar minhas práticas docentes à procura de vestígios de um possível deslocamento da posição marginal ajudará a intensificar propostas transformadoras. Atividades que devem enxergar na Educação a capacidade de despertar nos "sujeitos um interesse sobre as questões sociais e culturais, inerentes ao espírito humano, permitindo assim que as mudanças sociais aconteçam sem ocasionamentos de desordem" (DEWEY, 1959, apud WOSNIAK; LAMPERT, 2017, p. 77). Pensar sobre esse contato entre os indivíduos é importante porque nas ações educativas com pessoas que não têm contato com trans/travestis devemos levar em conta a causa desse afastamento. Perguntar-nos o que alimenta essa distância, e o quanto os participantes sabem sobre a nossa existência.

A emancipação do espectador de Rancière (2012) ajuda a esclarecer o que proponho aqui. Segundo o autor essa emancipação inicia-se a partir de uma redistribuição entre os papéis de ator e espectador. Ela

\begin{abstract}
Começa quando se compreende que olhar também é uma ação que confirma ou transforma essa distribuição das posições. O espectador também age, tal como o aluno ou o intelectual. Ele observa, seleciona, compara, interpreta. Relaciona o que vê com muitas outras coisas que viu em outras cenas, em outros tipos de lugares. Compõe seu próprio poema com os elementos do poema que tem diante de si. Participa da performance refazendo-a à sua maneira, furtando-se, por exemplo, a energia vital que esta deve transmitir para transformá-la em pura imagem e associar essa pura imagem a uma história que leu ou sonhou, viveu ou inventou. Assim, são ao mesmo tempo espectadores distantes e intérpretes ativos do espetáculo que lhes é proposto (RANCIÈRE, 2012, p. 17).
\end{abstract}

Dessa forma a simples presença de uma travesti numa cena de novela; o encontro com uma delas no supermercado ou a presença de uma professora trans aplicando uma oficina artística vai criando nas pessoas esse poema de que fala Rancière (2012). Consequentemente a ideia da travesti que só pode ser prostituta, sem querer aqui menosprezar o trabalho das garotas de programa, vai se desfazendo no imaginário social, pois "mesmo consideradas à margem da sociedade, elas sobrevivem, a exemplo das travestis estudantes, funcionárias públicas, educadoras, etc" (LUMA, 2012, p. 15). 


\section{Performance e oficinas repletas de pequenos gestos artivistas}

Como numa terapia hormonal sem indicação posológica profissional, aos moldes daquela realizada por diversas mulheres trans, eu conduzi essa procura por pistas de práticas estético-políticas desviantes dentro de minha curta, mas ativa e diversa, caminhada pelas Artes Visuais. Mas por que criei essa metáfora partindo de um tratamento endocrinológico? Bem, algumas mulheres trans/travestis fazem a terapia hormonal conhecendo a medicação e seus efeitos, mas devido à falta de assistência médica especializada acabam fazendo a prescrição por conta própria. Rotina que não segue uma linearidade e constância, mas sim o que lhes diz a imagem diante do espelho, ou seja, a vontade momentânea, diária, semanal ou mensal por um corpo socialmente e performativamente idealizado. Logo, como essa investigação também é aleatória, uma vez que se debruça de forma não linear sobre duas ações arte-educativas durante a análise que empreendo em busca de vestígios artivistas e militantes, a metáfora torna-se cabível e aproxima-se e interligase, epistemologicamente, com as questões que discuto nos estudos de gênero.

Do mesmo modo esse recorte contempla a Educação. Sendo assim, inicio essa jornada genealógica pela minha história artística tendo a perspectiva educacional como primeiro horizonte. Panorama decisivo para a mudança da realidade daquelas pessoas trans que dificilmente permanecem nas salas de aula. Consequentemente, o seu potencial artístico/educacional é podado. De acordo com Renata Felinto dos Santos (2019), professora e pesquisadora do revisionismo histórico, a marginalidade, invisibilidade e exclusão impostos a certos grupos humanos silencia/apaga suas criações, como foi o caso da "violência da escravidão que se transmuta em violência da subcidadania que, por sua vez, se converte em sub-representação" (SANTOS, 2019 , p. 343). Sobre o apagamento de pessoas trans na educação, Luma Nogueira de Andrade, primeira mulher trans doutora em educação no Brasil, diz que "a escola para a maioria das travestis permanece como um sonho" (ANDRADE, 2012, p. 15). Dayvi Santos, uma das egressas trans do Mestrado em Educação da UFPE, defende que "a escola, nesse contexto, aparece como um dos locais mais inóspitos para permanência daqueles que transitam entre os gêneros" (SANTOS; OLIVEIRA, 2019, p. 52).

Assim como Santos (2019), Fábio Rodrigues da Costa (2019), pesquisador/ professor das questões de dissidência de gênero, acredita que para mudarmos esse cenário no ensino de artes e na educação básica, poderíamos nos valer da decolonialidade, que "ocorreria por meio da inserção de artistas ativistas e artivistas LGBT na seleção das/os professoras/es". (COSTA, 2019, p. 199). Entretanto, conforme o pesquisador, a

Inserção não assegura um projeto educativo emancipatório. Isso porque o pensamento das professoras e dos professores tem sido colonizado muito antes de ingressarem nos cursos de formação inicial, temos sido colonizadas e colonizados ao longo da vida. Portanto, nossa colonização também ocorre nos cursos de licenciatura e procede quando de nosso ingresso nas redes 
de ensino (municipal, estadual e federal) como profissionais de educação. (COSTA, 2020, p. 199).

Pensando nisso, compreendo que a ação pedagógica transformadora precisará ir muito além da sala de aula. Deverá incluir práticas educativas não formais, modalidade que tem, na diferença metodológica e espaço-temporal, brechas apropriadas para a entrada desses agentes dissidentes. Nesse sentido, as Oficinas de Origami que realizei durante a Exposição Galhos no ano de 2017, viabilizaram minha entrada no cenário educacional que ocorre fora das salas de aula e possibilitaram o contato dos estudantes e professores com uma docente trans. Nestas ocasiões, recebi alunos de escolas públicas de ensino fundamental anos iniciais e finais. As/os professoras/es acompanhavam os estudantes durante os eventos e na interação comigo, enquanto docente/oficineira, estes agentes educacionais puderam vivenciar, indiretamente, a proximidade com as existências transgêneras. Hoje percebo que mesmo não tendo abordado temas LGBTIAP+ durante a oficina, a minha simples presença ali já era um imenso ato político/transformador, pois viabilizou o contato daquelas pessoas com uma docente transexual (Fig. 1).
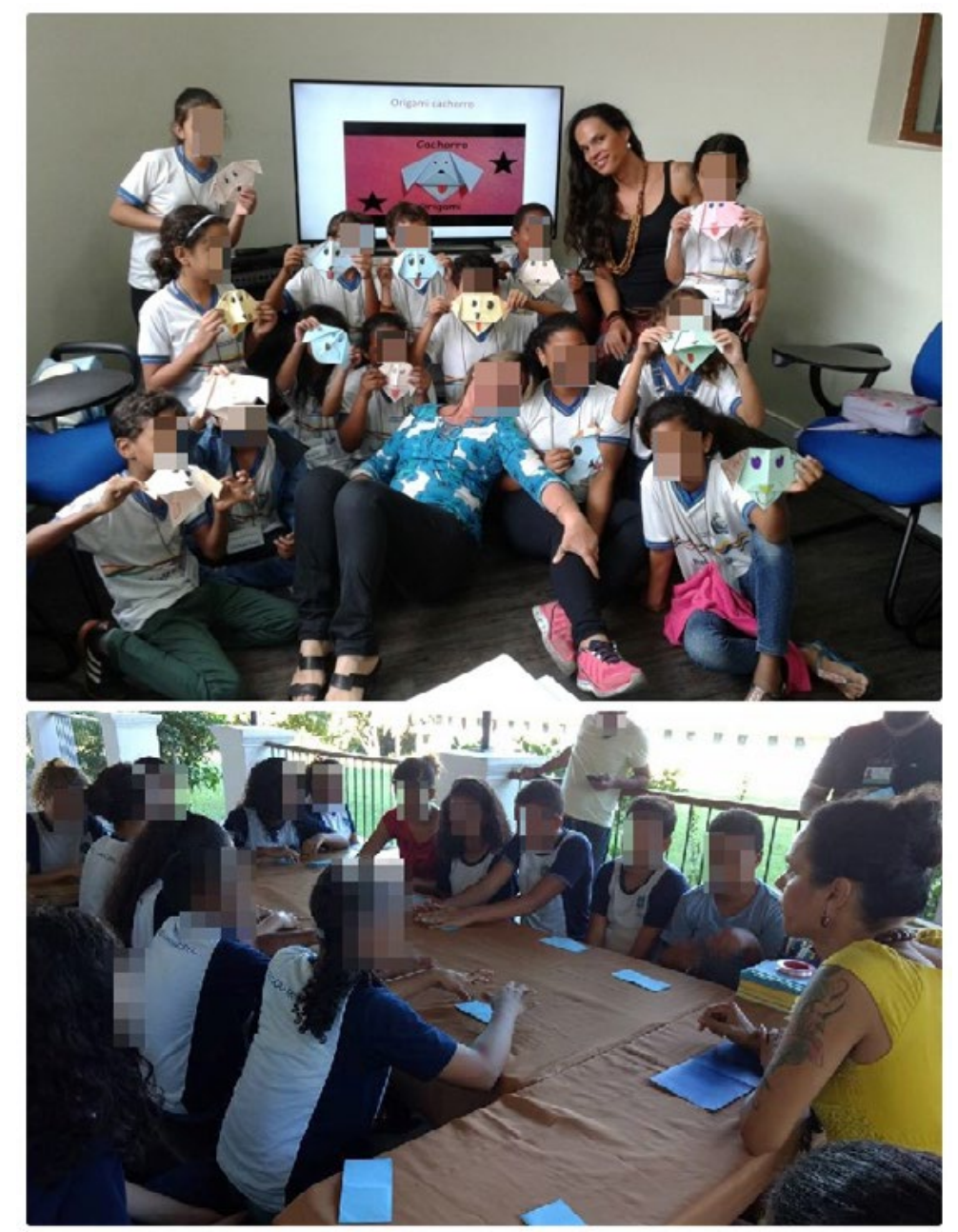

Figura 1 - Autoria desconhecida. Registos das oficinas de origami, 2017, fotografia, $15 \times 20 \mathrm{~cm}$. Fonte: a autora. 
No entanto, quando reobservo essas imagens admito que seja preciso fazer mais do que apenas estar presente. É preciso colocar subversão neste quadro de ação. Como exemplo desse desvio educacional, trago o pensamento de uma docente que ao ponderar sua postura em sala de aula e as práticas de silenciar, enquanto estava internamente tocada por uma experiência que havia acabado de fazer com sua turma, sugere o abandono do lugar de conforto e de costume. Assentos tradicionais que as educadoras precisam esquecer. Trata-se de Luciana Borre, a/r/tógrafa interessada nos estudos de gênero. Para ela é preciso arrancar as raízes crescidas nas cadeiras escolares, pois "se o desejo for o de promover mudanças, é necessário remover o lugar onde estão sentadas" (HERNÁNDEZ, 2000, p. 23 apud BORRE, 2020, p. 32).

Apesar de não estar confortavelmente sentada, eu, assim como muitas outras mulheres trans/travestis, fiquei imóvel durante muito tempo. Emparedada, apagada e invisibilizada como ocorre com as (os) modelos vivos na arte do mimetismo. Linguagem artística na qual a pessoa que modela é artisticamente fundida com a parede (fundo) sobre a qual posa. Hoje avalio esse tipo de performance como uma ação extremamente simbólica. Enxergo nas pinceladas do artista pintor que realiza a ação mimética a mão da sociedade que durante tantos anos tentava ocultar a presença de corpos trans.

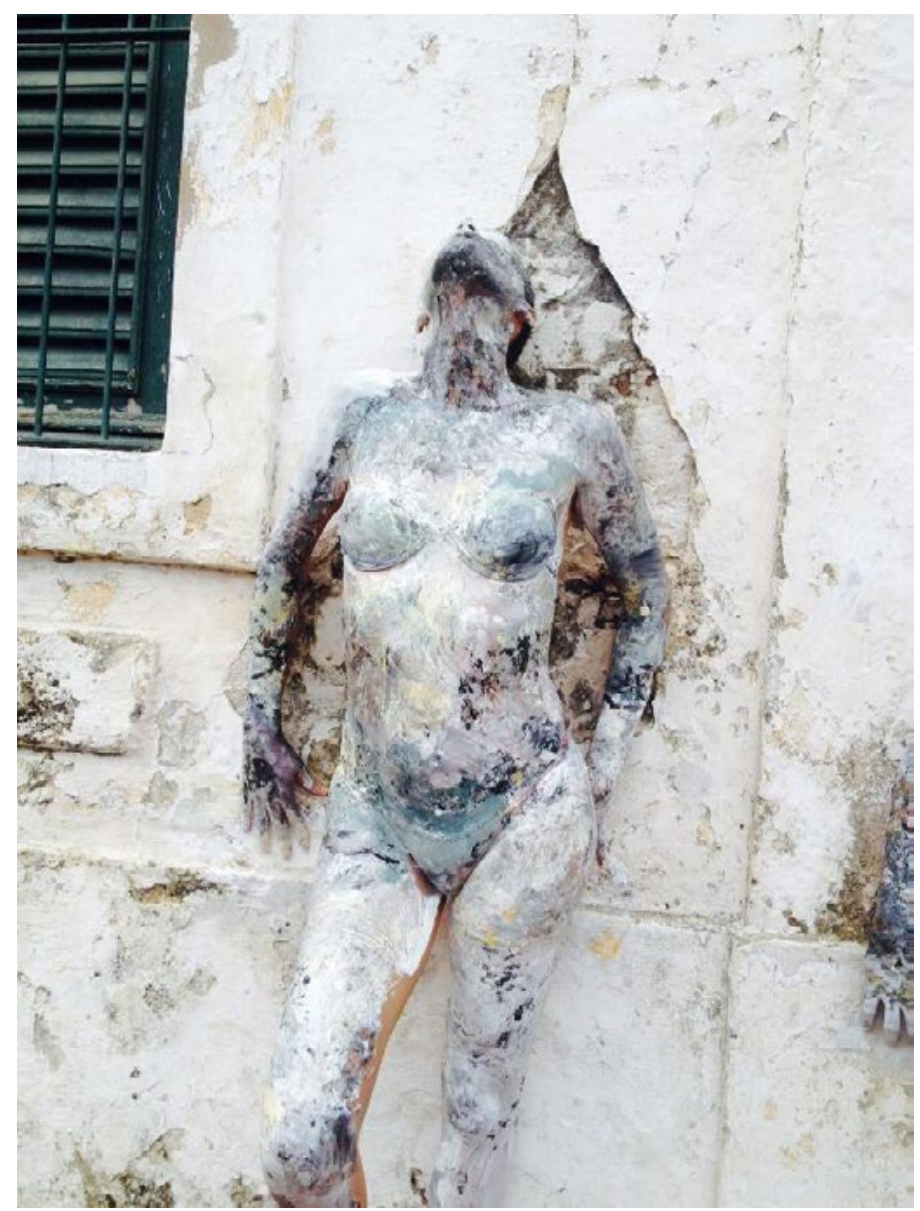

Figura 2 - Autoria desconhecida. Registro da Performance Mimetismo com pintura de Raurício Barbosa, 2014, fotografia, $20 \times 30 \mathrm{~cm}$. Fonte: a autora. 
Todavia, chega a hora de se levantar, como sugere Borre (2020). Fazer força e assumir uma postura diversa. Foi o que fiz. Mas antes de contar o que vem depois disso, sinto a necessidade de expor um fato que me deu força durante a ação retratada na Figura 2 - a fotografia foi enviada para minhas redes sociais dias após a performance e não lembro quem foi o seu autor, mas aproveito essa oportunidade para agradecer o envio da foto. Essa intervenção ocorreu em Olinda/PE, no Dia do Frevo em 2014. Naquele ano um grupo de passistas tentava quebrar o recorde de maior bloco de dançarinos de frevo do mundo. Consequentemente, o Largo do Mosteiro de São Bento estava cheio e escolhemos esta locação para atrair mais visibilidade. Porém, parece que Raurício Barbosa, artista maranhense que me pintou durante a performance, esqueceu que tinha convidado uma modelo trans. Não deu outra. Durante a ação uma senhora prostrou-se em frente a mim e começou a falar, como se eu não ouvisse, que o volume em minha calcinha era muito grande, Dizia ela: "não é possível, está muito grande!". A curiosa senhora só parou quando a produtora do evento foi até ela e disse: "senhora, a modelo pode lhe ouvir".

Nas palavras da inquieta senhora, estavam disfarçadas as estratégias daquilo que Santos e Oliveira (2019) chamam de Engenharia dos Corpos Normais. Para as autoras "a repressão ao 'desvio' deve ser pública e implacável, afinal, está em jogo a salvaguarda de um projeto social" (SANTOS; OLIVEIRA, 2019, p. 51). Plano a ser enfrentado sob um ponto de vista que encare essa empreitada como uma luta que

\footnotetext{
Somente tem sentido quando os oprimidos, ao buscarem recuperar sua humanidade, que é uma forma de criá-la, não se sentem idealistas opressores, nem se tornam de fato, opressores dos opressores, mas restauradores das humanidades em ambos. E está aí a grande tarefa humanista e histórica dos oprimidos - libertar-se a si e aos opressores (FREIRE, 2011, p. 41).
}

Mesmo concordando com o pensamento de Freire (2011), foi difícil ouvir aquelas palavras, mas pacientemente eu esperei e me acalmei. Não assumi o papel de opressora. Fiquei ali quieta recebendo a pintura e, metaforicamente, fui entrando na parede. Ao final eu estava imersa na performance, era como se o mimetismo me tornasse uma parte da centenária arquitetura do mosteiro, monumento que foi me passando força, apesar de representar uma Igreja que também, tradicionalmente, nunca me aceitou. Independente disso eu fui recebendo aquela energia e em torno de cinco minutos o artista me permitiu sair da pose. Mover-me e abandonar a parede. Contudo, hoje percebo que naquele dia eu não deixei só aquele pedaço de concreto histórico para trás. No ato de afastar-me estava embutido o abandono da invisibilidade compulsória imposta por tantos anos às transfeminilidades. Simbolicamente levantarme da cadeira tradicional de que fala Borre (2020).

A investigação aqui elaborada fez-me perceber o artivismo existente na Performance e nas oficinas, pois "a arte é considerada política porque mostra os estigmas da dominação, porque ridiculariza os ícones reinantes ou porque sai de seus 
lugares para transformar-se em prática social" (RANCIÈRE, 2012, p. 52). Refletindo sobre essa afirmação entendo que preciso aproximar as práticas artísticas que venho desenvolvendo, a partir desta postura artivista transfeminista, de minhas parceiras de experiência de gênero, de outras transfeminilidades e travestilidades. Sem esquecer as pessoas que não estão presentes na sigla LGBTIAP+. Porém neste instante é preciso manter o foco na comunidade transgênera e partilhar com suas representantes o conhecimento que tenho adquirido. Esse encontro pode ocorrer em locais que as agrupam ocasionalmente, como é o caso das ONGS que, eventualmente, promovem ações de retirada de documentos e outros serviços sociais. É a oportunidade ideal para pôr em prática o pensamento de Wosniak e Lampert, os quais, apoiando-se em John Dewey, defendem que "a arte deveria se situar ao lado das coisas da experiência comum da vida" (2017, p. 80), em outras palavras, ela precisaria estar "inserida em um contexto diretamente humano, ao contrário de estarem relegadas exclusivamente aos museus ou galerias compartimentadas em teorias que distanciam as experiências estéticas da vida cotidiana" (ibidem).

\section{Considerações Finais}

Ao reexaminar essas ações procurei despertar situações reflexivas e autoeducativas em torno da representatividade dos corpos dissidentes, uma vez que a linguagem não verbal é potente e carregada de simbolismos. Percebo agora que será por meio do convívio, da proximidade e da leitura de imagens que retratem as travestis, se possível criadas por elas, que as pessoas entenderão suas singularidades e subjetividades. Está aqui a maior ação estético-política que devo desempenhar. Apesar de ter em mente que "não há evidências de que o conhecimento de uma situação provoque o desejo de mudá-la" (RANCIÈRE, 2014, p. 29). Mas, mesmo não tendo certeza quanto à eficácia de minhas ações, eu pretendo seguir em frente e continuar afastando-me da parede do mosteiro.

Voltando as questões educacionais, e me apoiando nas leituras de Barbosa (2005), comparo as pessoas cis que não têm contato com pessoas trans, com crianças que possuem pouco acervo de vocabulário. Estou disposta a enriquecer este repertório por meio de minhas produções. É preciso educar através de visualidades que representem corpos trans, afinal "aprende-se a palavra visualizando" (BARBOSA, 2005 , p. 28). As práticas artísticas dissidentes criadas por meio de produções imagéticas e ações performáticas contribuem para a compreensão da corporalidade transgênera, pois "a representação plástica visual muito ajuda a comunicação verbal" (BARBOSA, 2005, p. 28). E é isso que preciso fazer; comunicar-me por meio de práticas artivistas e dissidentes.

As considerações que apresento ao final deste estudo são apenas o esboço de uma procura muito maior. $\bigcirc$ reolhar sobre oficinas e performances tornar-se-á uma constante em meu processo, consequentemente mudando a forma como lido 
com minhas produções, pois, de certa forma, deixava-as esquecidas. E falando em quebra de normas, a revisão de meus trabalhos confirmou que a atitude artivista estava presente desde a Performance Mimetismo. Ao reobservá-la ficou claro que, apesar dos comentários, a senhora tagarela esteve em contato com uma artista trans. Logo, da próxima vez que ela reencontrar uma dessas artistas, possivelmente, não terá a mesma reação, pois em sua memória aquele encontro estará registrado. $O$ mesmo posso dizer das alunas/os e professoras/es que foram as oficinas. Se antes daquela aula elas/es imaginavam ser impossível assistir uma aula com uma docente trans, depois daquele encontro essa impossibilidade foi apagada.

Considero a saída do muro do Mosteiro de Olinda o ponto alto dessa reavaliação e, juntamente com as oficinas, esse trabalho me chamou atenção para a importância de pensar exposições que possam se aproximar do grande público, abandonando, por hora, as salas dos museus e das galerias. Espaços estes que, normalmente, não são frequentados por pessoas travestis. Logo, uma artista que desejar mudar esta realidade com sua arte, deve levar esse dado em consideração.

Focando ainda mais nessa questão do público, acredito, a partir desta investigação, que o cerne desta busca repousou na mescla entre Artes Visuais e Educação, principalmente na Expo que foi feita juntamente com oficinas. Esse ponto específico encaminhará minhas ações futuras, pois entendo que saindo do museu e adentrando os espaços de convívio social não "destinados à arte" me aproximarei do público trans, mas também preciso destacar o papel educativo nestas ações, pois como atesta Luma Andrade "quanto mais diversificado for o campo de estudos sobre as travestis, maior será a possibilidade de compreendê-las" (2012, p. 17).

\section{Referências}

ANDRADE, Luma Nogueira de. Travestis na escola: assujeitamento e resistência à ordem normativa. 2012. Tese (Doutorado em Educação) - PPGE/UFC, Fortaleza, 2012, 279 f. Disponível em: http://www.repositorio.ufc.br/handle/riufc/7600. Acesso em: 17out2020.

BARBOSA, Ana Mae. A imagem no ensino da arte: anos oitenta e novos tempos. $6^{\mathrm{a}}$ ed. São Paulo: Perspectiva, 2005.

BAZANTE, Brenda Gomes. Corpocinetismo: relações entre a representação do corpo humano e esculturas cinéticas. Revista Apotheke, Florianópolis, v. 6, n. 2, p. 191-207, ago. 2020. Disponível em: https://revistas.udesc.br/index.php/apotheke/article/view/18337/11803. Acesso em: 16out.2020.

BENTO, Berenice. A reinvenção do corpo: sexualidade e gênero na experiência transexual. Rio de Janeiro: Garamond, 2006.

BORRE, Luciana. Bordando afetos na formação docente. Conceição da Feira: Andarilha Edições. 2020. 
BUTLER, Judith. Problemas de gênero: feminismo e subversão da identidade. 19a ed. São Paulo: Civilização Brasileira, 2020.

BUTLER, Judith. Quadros de guerra: quando a vida é passível de luto? São Paulo: Civilização Brasileira, 2018.

COSTA, Fábio José Rodrigues da. Ensino/aprendizagem das Artes Visuais na América Latina: colonialidade cultural e emocional associada a questões LGBT. Revista GEARTE, Porto Alegre, v. n. 2. p. 197-246, mai./ago. 2019. Disponível em: https://seer.ufrgs.br/gearte/article/ view/92908. Acesso em: 13 out2020.

DIAS, Belidson. A/r/tografia como Metodologia e Pedagogia em Artes. In: DIAS, Belidson; IRWIN, Rita L. Pesquisa educacional baseada em artes: A/r/tografia. Santa Maria: Ed. da UFSM, 2013.

FEDERICl, Silvia. Calibã e a bruxa: mulheres, corpo e acumulação primitiva. São Paulo: Elefante, 2017.

FOUCAULT, Michel. Microfísica do poder. Rio de Janeiro: Edições Graal, 1979.

FREIRE, Paulo. Pedagogia do oprimido. 50ª ed. Rio de Janeiro: Paz e Terra, 2011.

JESUS, Jaqueline Gomes de (Org) et al. Transfeminismo: teoria e práticas. Rio de Janeiro: Metanoia, 2014.

KLAUS, Viviane et al. Genealogia foucaultiana e políticas educacionais: possibilidades analíticas. Perspectiva, Florianópolis, v. 32, n.2, p. 665-687, mai./ago. 2015.Disponível em: https://periodicos.ufsc.br/index.php/perspectiva/article/view/2175-795X.2015v33n2p665. Acesso em: 12 out2020.

LOURO, Guacira Lopes. Um corpo estranho: ensaios sobre sexualidade e teoria queer. Belo Horizonte: Autêntica, 2004.

PRECIADO, Paul Beatriz. Manifesto contrassexual. Práticas subversivas de identidade sexual. São Paulo: n-1 edições, 2017.

RANCIÈRE, Jacques. O espectador emancipado. São Paulo: Martins Fontes, 2012.

SANTOS, Dayvi; OLIVEIRA, Anna Luiza Martins de. Trajetórias transgêneras na educação de jovens e adultos: conquistas, horizontes e ameaças entre tempos, espaços e sujeitos escolares. Série-Estudos, Campo Grande, MS, v. 24, n. 52, p. 49-75, set./dez. 2019. Disponível em: https://www.serie-estudos.ucdb.br/serie-estudos/article/view/1398/pdf. Acesso em: 17 out2020.

SANTOS, Renata Aparecida Felinto dos. A pálida história das Artes Visuais no Brasil: onde estamos negras e negros? Revista GEARTE, Porto Alegre, v. 6. n. 2, p, 341-368, mai./ago. 2019. Disponível em: https://seer.ufrgs.br/gearte/article/view/94288. Acesso em: 17out2020. 


\section{Revista Apotheke}

TOURINHO, Irene. Aspectos e fragmentos de narrativas sobre o visual na prática educativa. In: DIAS, Belidson; IRWIN, Rita L. Pesquisa educacional baseada em artes: A/r/tografia. Santa Maria: Ed. da UFSM, 2013.

WOSNIAK, Fábio; LAMPERT, Jociele. Sobre o ensino/aprendizagem em artes visuais ou arte como experiência. Revista Apotheke, Florianópolis, v. 3, n. 2, p. 76-92, jul. 2017. Disponível em: https://revistas.udesc.br/index.php/apotheke/article/view/10088. Acesso em: 13 out2020.

Submissão: $18 / 10 / 20$

Aceitação: 29/11/20 